Article

\title{
N-Type Semiconducting Behavior of Copper Octafluorophthalocyanine in an Organic Field-Effect Transistor
}

\author{
Akane Matumoto ${ }^{1}$, Norihisa Hoshino ${ }^{2}$, Tomoyuki Akutagawa ${ }^{2}$ and Masaki Matsuda ${ }^{1, *}$ \\ 1 Department of Chemistry, Kumamoto University, 2-39-1 Kurokami, Chuo-ku, Kumamoto 860-8555, Japan; \\ matsumoto.skm.ik@gmail.com \\ 2 Institute of Multidisciplinary Research for Advanced Materials, Tohoku University, 2-1-1 Katahira, \\ Sendai 980-8577, Japan; hoshino@tagen.tohoku.ac.jp (N.H.); akuta@tagen.tohoku.ac.jp (T.A.) \\ * Correspondence: masaki@kumamoto-u.ac.jp; Tel.: +81-96-342-3372
}

Received: 14 September 2017; Accepted: 25 October 2017; Published: 27 October 2017

\begin{abstract}
Based on the crystal structure analysis, the overlap integral between the frontier molecular orbitals of adjacent $\mathrm{F}_{8} \mathrm{CuPcs}$ in the one-dimensional chain is estimated: the overlap integral between the lowest unoccupied molecular orbitals is $5.4 \times 10^{-3}$, which is larger than that in a typical n-type semiconducing material $\mathrm{F}_{16} \mathrm{CuPc}\left(2.1 \times 10^{-3}\right)$, whereas that between the highest occupied molecular orbitals is $2.9 \times 10^{-4}$. Contrary to previous studies in air, we found that an organic field-effect transistor (OFET) composed of $\mathrm{F}_{8} \mathrm{CuPc}$ essentially shows clear n-type semiconducting behavior in vacuum.
\end{abstract}

Keywords: copper octafluorophthalocyanine; organic semiconductor; n-type semiconductor; OFET

\section{Introduction}

Metallophthalocyanines (MPcs) are widely used not only as organic dyes but also as organic semiconductors, owing to their high air and chemical stabilities. They are being actively studied as components of organic electronics, in applications such as organic field-effect transistors (OFETs), organic light-emitting diodes, and organic photovoltaic cells [1-3]. MPcs are used as hole transport/injection/extraction materials because the energy level of their highest occupied molecular orbital (HOMO), consisting of the $\pi$ orbital of the phthalocyanine $(\mathrm{Pc})$, matches well with the work function of ordinary hole injection/extraction electrodes such as Au or indium-tin-oxide (ITO) [4-6]. They show p-type semiconducting characteristics, with a field effect hole mobility of around $10^{-2} \mathrm{~cm}^{2} \mathrm{~V}^{-1} \mathrm{~s}^{-1}$ in thin film transistors and around $1 \mathrm{~cm}^{2} \mathrm{~V}^{-1} \mathrm{~s}^{-1}$ in single crystal transistors [1,7].

Introduction of electron-withdrawing groups onto the peripheral benzene rings of $\mathrm{Pc}$ is a valid approach for tuning the electronic properties of MPcs. For instance, $\mathrm{F}_{16} \mathrm{CuPc}$, a fully fluorinated $\mathrm{CuPc}$ shows n-type characteristics with an electron mobility comparable to its unsubstituted counterpart, $\mathrm{CuPc}$, a p-type material $[8,9]$. Therefore, $\mathrm{F}_{16} \mathrm{CuPc}$ has been widely used as an n-type material in organic electronics [10-13].

For n-type organic semiconductors, in order to obtain a low energy barrier at the interface, the position of the lowest unoccupied molecular orbital (LUMO) should be close to the work function of the electrode. Moreover, a large $\pi-\pi$ overlap of the LUMOs between the adjacent molecules in the crystal is preferred [14], because electron transport in the crystalline state occurs through the overlapped LUMOs. As for the LUMO level of $\mathrm{F}_{8} \mathrm{CuPc}$ (Figure 1), the reported value, $-3.91 \mathrm{eV}$ [15], is similar to that of $\mathrm{C}_{60}$ and its derivatives $[16,17]$. This implies that the LUMO level of $\mathrm{F}_{8} \mathrm{CuPc}$ is positioned optimally to enable it to function as an n-type organic semiconductor, and that $\mathrm{F}_{8} \mathrm{CuPc}$ can 
be potentially used as an electron transport/injection/extraction material in organic electronics, similar to $\mathrm{C}_{60}$. Indeed, the junction between $\mathrm{F}_{8} \mathrm{CuPc}$ and $\mathrm{p}$-type MPc has been reported to exhibit a rectification effect $[18,19]$. In contrast, the highest occupied molecular orbital (HOMO) level of $\mathrm{F}_{8} \mathrm{CuPc}$ has been reported to be $-6.06 \mathrm{eV}$ [15]. This value is far from the work function of Au or ITO [5,6]. Therefore, we expected $\mathrm{F}_{8} \mathrm{CuPc}$ to be an n-type semiconductor. However, recently, thin film or single crystal transistors composed of $\mathrm{F}_{8} \mathrm{CuPc}$ have been reported to show ambipolar characteristics in air $[20,21]$.

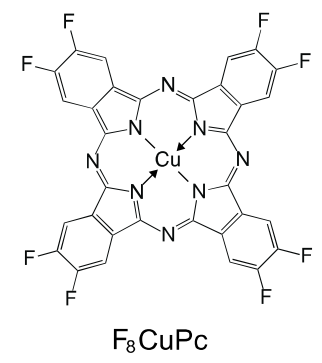

Figure 1. Structural formula of $\mathrm{F}_{8} \mathrm{CuPc}$.

In this study, we grew a single crystal of $\mathrm{F}_{8} \mathrm{CuPc}$, and determined its crystal structure to estimate the $\pi-\pi$ overlap between the frontier orbitals of adjacent molecules by the extended Hückel calculation. We have also examined the charge transport properties of OFETs based on $\mathrm{F}_{8} \mathrm{CuPc}$ thin films, and discovered that the transistor is unstable in air, whereas it shows stable n-type transport properties in vacuum.

\section{Materials and Methods}

\subsection{Synthetic and Crystallisation Procedures}

All reagents were used as received without further purifications. $5.1 \mathrm{~g}(30 \mathrm{mmol})$ of $\mathrm{CuCl}_{2} \cdot 2 \mathrm{H}_{2} \mathrm{O}$ (WAKO) was heated and dried under vacuum, and $5.0 \mathrm{~g}(30 \mathrm{mmol})$ of 4,5-difluorophthalonitrile (TCI) and $10 \mathrm{~mL}$ of $\mathrm{N}, \mathrm{N}$-dimethylformamide (Super Dehydrated grade, WAKO) were added. The mixture was refluxed under Ar for $6 \mathrm{~h}$, and filtered. A bluish-purple powder of $\mathrm{F}_{8} \mathrm{CuPc}$ was obtained, which was washed several times with acetone to yield $2.3 \mathrm{~g}(42 \%)$ of the product. Single crystals of $\mathrm{F}_{8} \mathrm{CuPc}$ were grown from this, by vacuum sublimation at $380^{\circ} \mathrm{C}$ under a pressure less than $40 \mathrm{~Pa}$.

\subsection{X-ray Diffraction (XRD) Measurements}

Although single-crystal X-ray diffraction (XRD) measurements were performed and the molecular arrangement of $\mathrm{F}_{8} \mathrm{CuPc}$ has been revealed in [21], the atomic coordinates are not available. Therefore, XRD data was collected for a single crystal of $\mathrm{F}_{8} \mathrm{CuPc}$, using an automated Rigaku Rapid system with the monochromated $\mathrm{Cu}-\mathrm{K} \alpha$ radiation $(\lambda=1.54187 \AA)$. The structure was solved using a direct method, using SIR2004 [22] and refined by a full-matrix least-squares technique with SHELXL-2014/7 [23] with anisotropic and isotropic thermal parameters for non-hydrogen and hydrogen atoms, respectively. The crystallographic data has been deposited at the Cambridge Crystallographic Data Centre (CCDC) as CCDC-1531473. Crystal data for $\mathrm{F}_{8}$ CuPc: Triclinic, $P \overline{1}, a=3.62740(10) \AA, b=12.7357(4) \AA$, $c=13.4538(4) \AA, \alpha=95.079(9)^{\circ}, \beta=90.529(6)^{\circ}, \gamma=96.441(6)^{\circ}$, and $V=615.07(3) \AA^{3}, Z=1, F(000)=357$, $d_{\mathrm{cal}}=1.944 \mathrm{~g} \mathrm{~cm}^{-3}, \mu(\mathrm{CuK} \alpha)=2.231 \mathrm{~mm}^{-1}(\lambda=1.54187 \AA), R_{1}=0.0879, \mathrm{w} R_{2}=0.2008, \mathrm{GoF}=0.999$.

\subsection{Fabrication of OFET and Measurement of the Transport Properties}

A thin film organic field effect transistor composed of $\mathrm{F}_{8} \mathrm{CuPc}$ was fabricated by the vacuum deposition of $\mathrm{F}_{8} \mathrm{CuPc}$ on a $\mathrm{SiO}_{2} / \mathrm{n}$-Si substrate under a pressure less than $1 \times 10^{-2} \mathrm{~Pa}$, where, $\mathrm{n}-\mathrm{Si}$ and $\mathrm{SiO}_{2}$ work as gate electrode and gate insulating layers, respectively. The deposition rate was ca. $0.05 \mathrm{~nm} \mathrm{~s}^{-1}$, and the resulting thickness of the film was ca. $30 \mathrm{~nm}$. Subsequently, $30 \mathrm{~nm}$ thick Al 
electrodes were deposited on the $\mathrm{F}_{8} \mathrm{CuPc}$ film to serve as the source and drain electrodes, under a pressure less than $1 \times 10^{-3} \mathrm{~Pa}$. Current-voltage characteristics were measured by an ADCMT 8252 electrometer in air or vacuum $\left(\sim 10^{2} \mathrm{~Pa}\right.$ and less than $\left.10^{-2} \mathrm{~Pa}\right)$.

\section{Results and Discussion}

The lattice constant of the $\mathrm{F}_{8} \mathrm{CuPc}$ crystal is consistent with those reported in [21]. The crystal structure is shown in Figure 2. $\mathrm{F}_{8} \mathrm{CuPc}$ forms a one-dimensional regular chain along the $a$-axis with an interplanar distance of $3.30 \AA$, which is smaller than the sum of the van der Waals radii of $\mathrm{sp}^{2}$ carbons, suggesting a strong $\pi-\pi$ intermolecular interaction. As the charge transport in organic semiconductors occurs via the $\pi$-electrons, a strong $\pi-\pi$ intermolecular interaction in the crystalline state is desirable, which can be evaluated by the overlap integral in the conduction path consisting of $\pi$-orbitals. Using an extended Hückel calculation method (The extended Hückel calculation was performed using CAESAR 2 software developed by PrimeColor Software, Inc. (Raleigh, NC, USA) Default parameters were used for the calculations), the overlap integral between the $\pi$-orbitals of adjacent $\mathrm{F}_{8} \mathrm{CuPcs}$ in the one-dimensional chain along the $a$-axis were estimated: the overlap integral between the LUMOs was found to be $5.4 \times 10^{-3}$, which is comparable to that of molecular conductors consisting of MPcs [24], whereas that the between HOMOs was $2.9 \times 10^{-4}$. In addition to the optimal position of the LUMO level, the $\pi-\pi$ overlap appears to favor electron transfer over hole transfer.

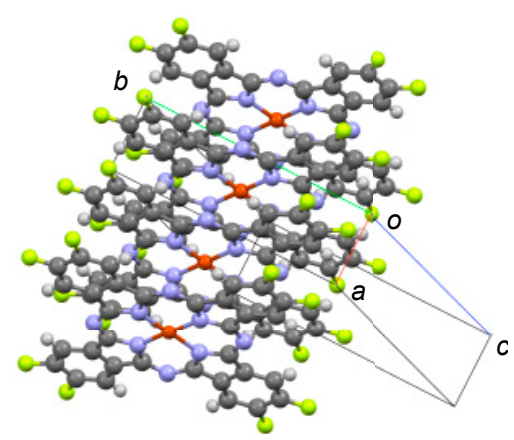

Figure 2. One-dimensional molecular arrangement of $\mathrm{F}_{8} \mathrm{CuPc}$ along the $a$-axis.

The carrier mobility of an organic thin film depends on the molecular orientation in the film. Figure 3 shows the X-ray diffraction pattern of the $\mathrm{F}_{8} \mathrm{CuPc}$ film deposited on a $\mathrm{SiO}_{2} / \mathrm{n}$-Si substrate. A peak at $2 \theta=6.56^{\circ}$, corresponding to (001) plane was observed, indicating that the crystallographic $c$-axis of $\mathrm{F}_{8} \mathrm{CuPc}$ in the as-deposited film is perpendicular to the substrate surface. This orientation is favorable for charge transport between the source and drain electrodes of an OFET (vide infra), because the $\pi-\pi$ overlap between adjacent $\mathrm{F}_{8} \mathrm{CuPc}$ molecules in the one-dimensional chain lies on the substrate.

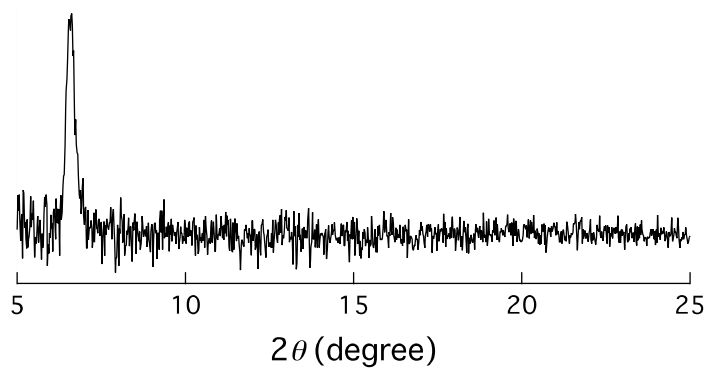

Figure 3. X-ray diffraction pattern of an $\mathrm{F}_{8} \mathrm{CuPc}$ film deposited on a $\mathrm{SiO}_{2} / \mathrm{n}-\mathrm{Si}$ substrate.

An OFET composed of $\mathrm{F}_{8} \mathrm{CuPc}$ was fabricated using a $\mathrm{SiO}_{2} / \mathrm{n}-\mathrm{Si}$ substrate and $\mathrm{Al}$ electrodes. Figure 4 shows a schematic of the fabricated transistor and its current-voltage characteristics measured 
in air. $\mathrm{F}_{8} \mathrm{CuPc}$ shows an n-type semiconducting behavior. However, parabolic current-voltage curves exhibiting a large hysteresis were obtained, although the first half of each measurement was consistent with the current-voltage characteristics reported previously [20]. Furthermore, the results could not be reproduced in repeated measurements. Figure 5 shows the current-voltage characteristics measured in vacuum $\left(\sim 10^{2} \mathrm{~Pa}\right)$. Compared to the measurement in air, it is obvious that the instability is rather suppressed. These features indicate that the $\mathrm{F}_{8} \mathrm{CuPc}$ transistor is unstable in air, and therefore, it is difficult to evaluate the transistor characteristics under air. In fact, we could not observe the reported ambipolar characteristics under air $[20,21]$ even when Au was used as the source and drain electrodes. On the other hand, Figure 6 shows the current-voltage characteristics measured under high vacuum (under a pressure less than $10^{-2} \mathrm{~Pa}$ ). $\mathrm{F}_{8} \mathrm{CuPc}$ shows a typical, stable n-type semiconducting behavior in vacuum, and the field effect electron mobility in the thin film transistor was calculated to be $7.9 \times 10^{-4} \mathrm{~cm}^{2} \mathrm{~V}^{-1} \mathrm{~s}^{-1}$ (on/off ratio being $3.6 \times 10^{3}$ ). Obviously, the p-type characteristics could not be found in high vacuum, irrespective of the source and drain electrodes.

(a)

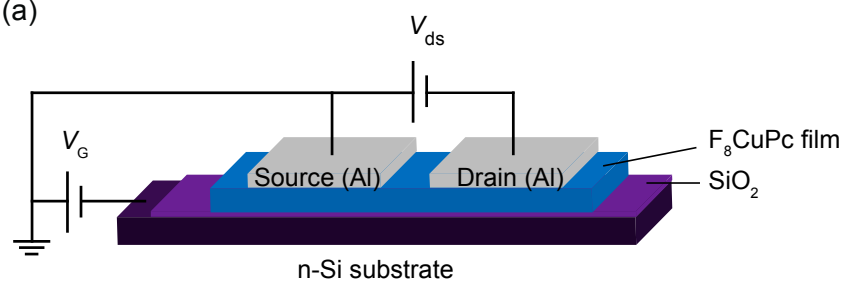

(b)

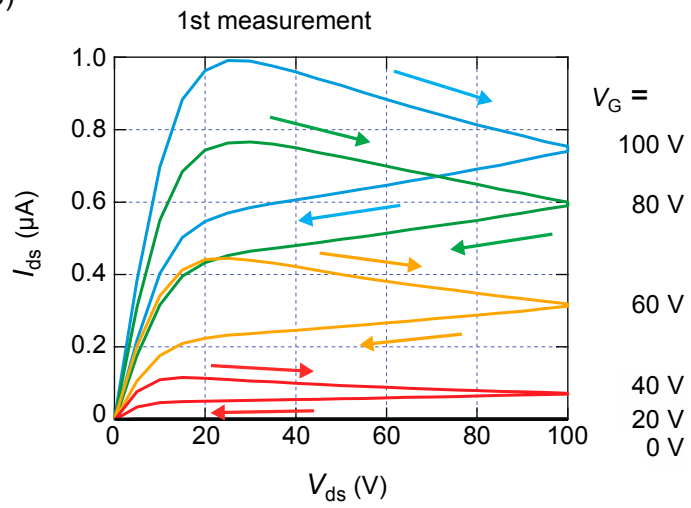

(c)

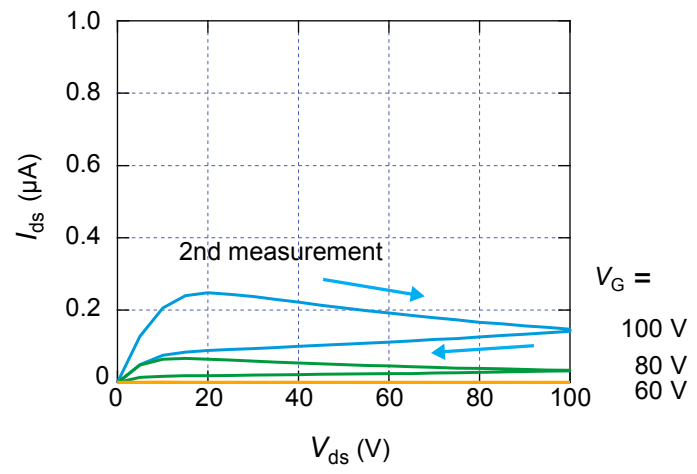

Figure 4. (a) Schematic of an $\mathrm{F}_{8} \mathrm{CuPc}$ film transistor; (b) current-voltage characteristics of the $\mathrm{F}_{8} \mathrm{CuPc}$ film transistor measured in air; and (c) those obtained from repeated measurements; these were performed immediately after the first. 


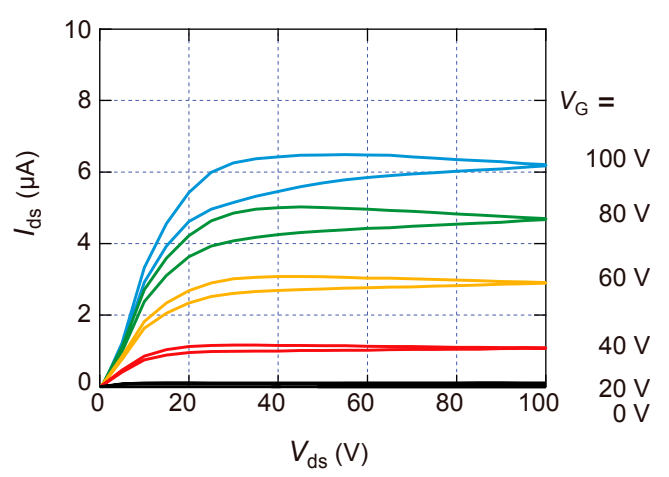

Figure 5. Current-voltage characteristics of the $\mathrm{F}_{8} \mathrm{CuPc} n$-channel transistor in vacuum $\left(\sim 10^{2} \mathrm{~Pa}\right)$.

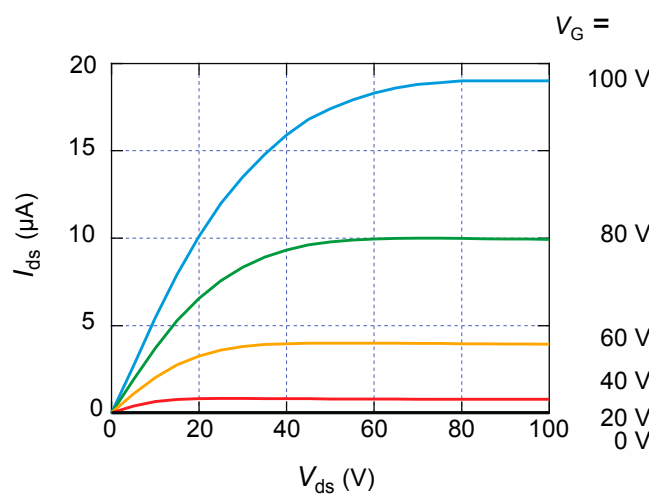

Figure 6. Current-voltage characteristics of the $\mathrm{F}_{8} \mathrm{CuPc}$-channel transistor in high vacuum (less than $\left.10^{-2} \mathrm{~Pa}\right)$.

As for an n-channel $\mathrm{F}_{16} \mathrm{CuPc}$ transistor, it has been previously shown that the $\mathrm{F}_{16} \mathrm{CuPc}$ film could be rendered air-stable by the introduction of $\mathrm{F}$ atoms [8]; fluorination renders the organic molecules resistant to oxidation, because the energy levels of their frontier orbitals are lowered. It has also been suggested that the conformational orientation of the $\mathrm{F}_{16} \mathrm{CuPc}$ molecules in the film with the F-atoms being exposed to air prevents the penetration of moisture into the film [8]. Photoemission spectroscopies revealed that the energy levels of the frontier orbitals of $\mathrm{F}_{8} \mathrm{MPc}$ are positioned between those of MPc and $\mathrm{F}_{16} \mathrm{MPc}[15,25]$. Therefore, they are clearly lower than that of MPc, and higher than that of $\mathrm{F}_{16} \mathrm{MPc}$. Consequently, $\mathrm{F}_{8} \mathrm{CuPc}$ could be more readily oxidized compared to $\mathrm{F}_{16} \mathrm{CuPc}$. Furthermore, the un-substituted $\mathrm{H}$-atoms in the benzene ring of $\mathrm{F}_{8} \mathrm{CuPc}$ and the attendant changes in the molecular arrangement in the crystal structure might permit moisture to penetrate through the thin film. Apparently, these factors are responsible for the air instability of the fabricated n-channel $\mathrm{F}_{8} \mathrm{CuPc}$ film transistor.

The field effect electron mobility of $7.9 \times 10^{-4} \mathrm{~cm}^{2} \mathrm{~V}^{-1} \mathrm{~s}^{-1}$ is almost 10 times lower than that of the $\mathrm{F}_{16} \mathrm{CuPc}$ film transistor; Bao et al. reported a field effect electron mobility of $5 \times 10^{-3} \mathrm{~cm}^{2} \mathrm{~V}^{-1} \mathrm{~s}^{-1}$ for the $\mathrm{F}_{16} \mathrm{CuPc}$ thin film transistor [8], and we too obtained a similar value with our measurement system. As for the electron transport, the overlap of the LUMOs is responsible for the transport. In the case of $\mathrm{F}_{16} \mathrm{CuPc}$, the overlap integral between the LUMOs of adjacent $\mathrm{F}_{16} \mathrm{CuPcs}$ in the one-dimensional chain could be estimated to be $2.1 \times 10^{-3}$, according to the crystal data in [26]. Despite the larger overlap integral between the LUMOs, the $\mathrm{F}_{8} \mathrm{CuPc}$ film transistor shows smaller electron mobility compared to that of the $\mathrm{F}_{16} \mathrm{CuPc}$ film transistor. The lower electron mobility in the $\mathrm{F}_{8} \mathrm{CuPc}$ film transistor could be attributed to the relatively low crystallinity in the as-deposited film, as indicated by the broad diffraction peak observed in Figure 3, whereas sharp diffraction peaks suggesting high crystallinity were observed in the $\mathrm{F}_{16} \mathrm{CuPc}$ film [8]. When a single crystal of $\mathrm{F}_{16} \mathrm{CuPc}$ was used, the field effect electron mobility of the $\mathrm{F}_{16} \mathrm{CuPc}$ transistor increased by two orders of magnitude [9]. 
This implies that higher field effect electron mobility could be obtained for $\mathrm{F}_{8} \mathrm{CuPc}$, if a single crystal is used. Indeed, a recent study on a single-crystal transistor of $\mathrm{F}_{8} \mathrm{CuPc}$ demonstrated that the field effect electron mobility of $\mathrm{F}_{8} \mathrm{CuPc}$ is comparable to that of $\mathrm{F}_{16} \mathrm{CuPc}$ [21], even though the measurements were performed in air.

\section{Conclusions}

Based on the crystal structure analysis, we have estimated the overlap integral between the LUMOs of adjacent molecules along the $a$-axis of the one-dimensional regular chain of $\mathrm{F}_{8} \mathrm{CuPc}$, and discovered that it is larger than that in a typical n-type semiconducting material $\mathrm{F}_{16} \mathrm{CuPc}$. The $\mathrm{X}$-ray diffraction pattern shows a peak attributable to (001) plane, implying that the one-dimensional chain in the as-deposited $\mathrm{F}_{8} \mathrm{CuPc}$ film lies on the substrate. A field-effect transistor composed of an $\mathrm{F}_{8} \mathrm{CuPc}$ film on a $\mathrm{SiO}_{2} / \mathrm{n}$-Si substrate clearly shows n-type semiconducting behavior with the field effect electron mobility of $7.9 \times 10^{-4} \mathrm{~cm}^{2} \mathrm{~V}^{-1} \mathrm{~s}^{-1}$ in vacuum, while being unstable in air. The larger overlap integral between the LUMOs in $\mathrm{F}_{8} \mathrm{CuPc}$ compared to that in $\mathrm{F}_{16} \mathrm{CuPc}$ implies that the electron mobility of $\mathrm{F}_{8} \mathrm{CuPc}$ could potentially exceed that of $\mathrm{F}_{16} \mathrm{CuPc}$. Considering the LUMO level and the electron transport properties, $\mathrm{F}_{8} \mathrm{MPcs}$ are good candidates for n-type semiconduction in organic electronics.

Acknowledgments: This study was supported in part by a Grant-in-Aid for Scientific Research (C) (No. 16K05752) from the Japan Society for the Promotion of Science.

Author Contributions: M.M. and A.M. conceived and designed the experiments; A.M. and N.H. performed the experiments; M.M., N.H. and T.A. analyzed the data; M.M. wrote the paper.

Conflicts of Interest: The authors declare no conflict of interest.

\section{References}

1. Bao, Z.; Lovinger, A.J.; Dodabalapur, A. Organic field-effect transistors with high mobility based on copper phthalocyanine. Appl. Phys. Lett. 1996, 69, 3066-3068. [CrossRef]

2. Tang, C.W.; van Slyke, S.A. Organic electroluminescent diodes. Appl. Phys. Lett. 1987, 51, 913-915. [CrossRef]

3. Tang, C.W. Two-layer organic photovoltaic cell. Appl. Phys. Lett. 1986, 48, 183-185. [CrossRef]

4. Liu, Z.; Zhang, Z.; Zhang, Y.; Jiang, J. Theoretical investigation of the molecular, electronic structures and vibrational spectra of a series of first transition metal phthalocyanines. Spectrochim. Acta A 2007, 67, 1232-1246. [CrossRef] [PubMed]

5. Anderson, P.A. Work function of gold. Phys. Rev. 1959, 115, 553-554. [CrossRef]

6. Park, Y.; Choong, V.; Gao, Y. Work function of indium tin oxide transparent conductor measured by photoelectron spectroscopy. Appl. Phys. Lett. 1996, 68, 2699-2701. [CrossRef]

7. Reese, C.; Bao, Z. Organic single-crystal field effect transistors. Mater. Today 2007, 10, 20-27. [CrossRef]

8. Bao, Z.; Lovinger, A.J.; Brown, J. Air-stable $n$-channel organic thin film transistors. J. Am. Chem. Soc. 1998, 120, 207-208. [CrossRef]

9. Jiang, H.; Ye, J.; Hu, P.; Wei, F.; Du, K.; Wang, N.; Ba, T.; Feng, S.; Kloc, C. Fluorinaion of metal phthalocyanines: Single-crystal growth, efficient $\mathrm{n}$-channel organic field-effect transistors, and structure-property relationships. Sci. Rep. 2014, 4, 7573. [CrossRef] [PubMed]

10. Jiang, X.; Wang, H.; Geng, Y.; Yan, D. Organic photovoltaic cells using hexadecafluorophthlaocyaninatocopper $\left(\mathrm{F}_{16} \mathrm{CuPc}\right)$ as electron acceptor material. Chem. Phys. Lett. 2007, 446, 329-332. [CrossRef]

11. Jea, M.; Kumar, A.; Cho, H.; Yang, D.; Shim, H.; Palai, A.; Pyo, S. An organic microcrystal array-embedded layer: Highly directional alternating $\mathrm{p}$ - and n-channels for ambipolar transistors and inverters. J. Mater. Chem. C 2014, 2, 3980-3987. [CrossRef]

12. Li, Q.; Ding, S.; Zhu, W.; Feng, L.; Dong, H.; Hu, W. Recent advances in one-dimensional organic p-n heterojunctions for optoelectronic device applications. J. Mater. Chem. C 2016, 4, 9388-9398. [CrossRef]

13. Optiz, A.; Wilke, A.; Amsalem, P.; Oehzelt, M.; Blum, R.-P.; Rabe, J.P.; Mizokuro, T.; Hörmann, U.; Moons, E.; Koch, N. Organic heterojunctions: Contact-induced molecular reorientation, interface states, and charge re-distribution. Sci. Rep. 2016, 6, 21291. [CrossRef] [PubMed] 
14. Newman, C.R.; Frisbie, C.D.; Filho, D.A.S.; Brédas, J.-L.; Ewbank, P.C.; Mann, K. Introduction to organic thin film transistors and design of n-channel organic semiconductors. Chem. Mater. 2004, 16, 4436-4451. [CrossRef]

15. Murdey, R.; Sato, N.; Bouvet, M. Frontier electronic structures in fluorinated copper phthalocyanine thin films studied using ultraviolet and inverse photoemission spectroscopies. Mol. Cryst. Liq. Cryst. 2006, 455, 211-218. [CrossRef]

16. Matsumoto, F.; Iwai, T.; Moriwaki, K.; Takao, Y.; Ito, T.; Mizuno, T.; Ohno, T. Design of fullerene derivatives for stabilizing LUMO energy using donor groups placed in spatial proximity to the $\mathrm{C}_{60}$ cage. J. Org. Chem. 2012, 77, 9038-9043. [CrossRef] [PubMed]

17. Li, C.-Z.; Tip, H.-L.; Jen, A.K. Functional fullerenes for organic photovoltaics. J. Mater. Chem. 2012, 22, 4161-4177. [CrossRef]

18. Anderson, T.L.; Komplin, G.C.; Pietro, W.J. Rectifying junctions in peripherally-substituted metallophthalocyanine bilayer films. J. Phys. Chem. 1993, 97, 6577-6578. [CrossRef]

19. Pietro, W.J. Rectifying junctions on metallophthalocyanine thin films. Adv. Mater. 1994, 6, 239-242. [CrossRef]

20. Shao, X.; Wang, S.; Li, X.; Chen, T.; Xiao, Y. Single component p- ambipolar and n-type OTFTs based on fluorinated copper phthlaocyanines. Dyes Pigments 2016, 132, 378-386. [CrossRef]

21. Jiang, H.; Hu, P.; Ye, J.; Li, Y.; Li, H.; Zhang, X.; Li, R.; Dong, H.; Hu, W.; Kloc, C. Molecular crystal engineering: Tuning organic semiconductor from p-type to n-type by adjusting their substitutional symmetry. Adv. Mater. 2017, 29, 1605053. [CrossRef] [PubMed]

22. Burla, M.C.; Caliandro, R.; Camalli, M.; Carrozzini, B.; Cascarano, G.L.; De Caro, L.; Giacovazzo, C.; Polidori, G.; Spagna, R. SIR2004: An improved tool for crystal structure determination and refinement. J. Appl. Cryst. 2005, 38, 381-388. [CrossRef]

23. Sheldrick, G.M. Crystal structure refinement with SHELXL. Acta Cryst. 2015, C71, 3-8.

24. Inabe, T.; Tajima, H. Phthlalocyanines-Versatile components of molecular conductors. Chem. Rev. 2004, 104, 5503-5533. [CrossRef] [PubMed]

25. Mayer, T.; Hunger, R.; Klein, A.; Jaegermann, W. Engineering the line up of electronic energy levels at inorganic-organic semiconductor interfaces by variation of surface termination and by substitution. Phys. Status Solidi (b) 2008, 245, 1838-1848. [CrossRef]

26. Yoon, S.M.; Song, H.J.; Hwang, I.-C.; Kim, S.; Choi, H.C. Single crystal structure of copper hexadecafluorophthalocyanine (F16CuPc) ribbon. Chem. Commun. 2010, 46, 231-233. [CrossRef] [PubMed] 